\title{
Hydrocephalus in an infant with trisomy 22
}

\author{
Fahmi Fahmi, Susan Schmerler, R Gordon Hutcheon
}

\begin{abstract}
We present an infant with true trisomy 22. Mosaicism is ruled out by the finding of a 47,XX, +22 karyotype in all cells analysed originating from two embryonic germ layers. The physical findings are consistent with the previously noted features including developmental delay, ear abnormalities, micrognathia, clefting, and congenital heart disease. The patient is the first described with macrocephaly and hydrocephalus and the second with holoprosencephaly.
\end{abstract}

( $(\mathcal{F}$ Med Genet 1994;31:141-144)

Trisomy 22 is a rare syndrome as evidenced by the paucity of affected live born infants described in published reports. A complete and accurate clinical description had been difficult to compile. Some reports were based on inadequate, prebanding chromosome delineation and others did not rule out mosaicism.

We report an infant with prenatally diagnosed trisomy 22. The physical examination and necropsy findings are compared with those previously published. Of particular note is the fact that our patient is the first reported with macrocephaly and hydrocephalus and the second with holoprosencephaly.

\section{Department of \\ Pediatrics, St Joseph's Hospital and Medical Center, 703 Main Street, Paterson, New Jersey 07503, USA \\ F Fahmi}

Department of Pediatrics, Section of Genetics, St Joseph's Hospital and Medical Center, Paterson, NJ, USA

S Schmerler

\section{Departments of}

Pediatrics and

Obstetrics, Section of

Genetics, St Joseph's

Hospital and Medical

Center, Paterson, NJ,

USA

R G Hutcheon

Correspondence to Dr Fahmi.

Received 27 August 1993. Accepted for publication 29 September 1993

\section{Case report}

The patient, a female infant, was the product of a term pregnancy to a 40 year old $\mathrm{G6,P1}, \mathrm{Ab} 4$ woman. Amniocentesis, discussed because of risks associated with maternal age and multiple miscarriages, was declined. An ultrasound evaluation at 22 weeks of gestation showed that the fetus had dilatation of the right cerebral ventricle, a cleft lip, and a prominent nuchal fold (fig 1). Increased concerns about fetal chromosomal abnormalities were raised by the physical findings and discussed with the family. At that point, they felt that fetal chromosome analysis was warranted.

The fetus was found to have a $47, \mathrm{XX},+22$ karyotype (fig 2). The $\alpha$ fetoprotein was within normal limits. The implications of these findings were reviewed with the parents who elected to continue the pregnancy.

The infant was delivered at term by primary caesarean section because of hydrocephalus. Her Apgar scores were 5 at one minute and 7 at five minutes. She weighed $2690 \mathrm{~g}$ (10th cent- ile), was $47 \mathrm{~cm}$ long (10th centile), and had a head circumference of $45.5 \mathrm{~cm}$ ( $>95$ th centile, 50 th centile for 12 months). The craniofacial examination was notable for macrocephaly, a large anterior fontanelle, low set ears, hypertelorism, epicanthic folds, downward slanting palpebral fissures, a flat nasal bridge, a long philtrum, a cleft of the right upper lip and of the palate, micrognathia, and a short neck with redundant skin (fig 3). Examination of the right eye showed a large inferior coloboma of the disc and retina, with a benign cyst infer-
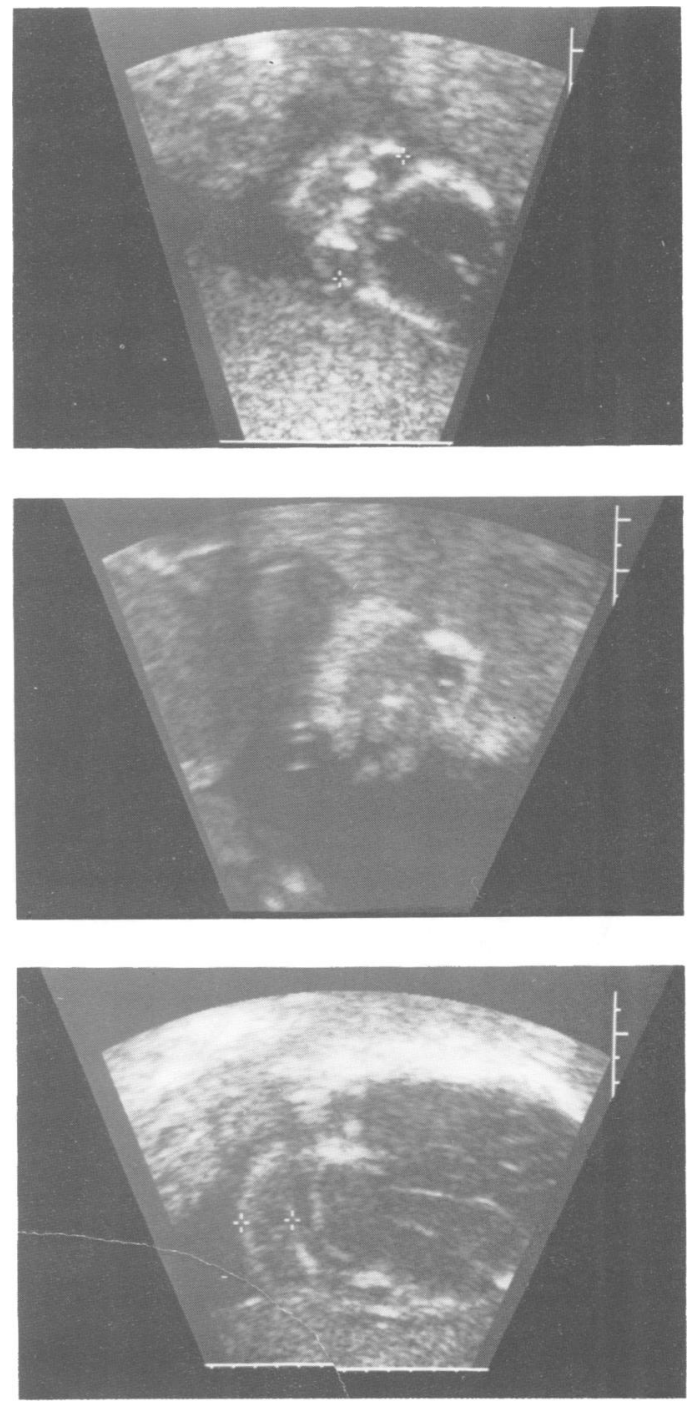

Figure 1 Antenatal ultrasound at 22 weeks' gestation showing: (top) head with dilated ventricles and hypertelorism, (middle) face with cleft lip, (bottom) thick nuchal fold. 

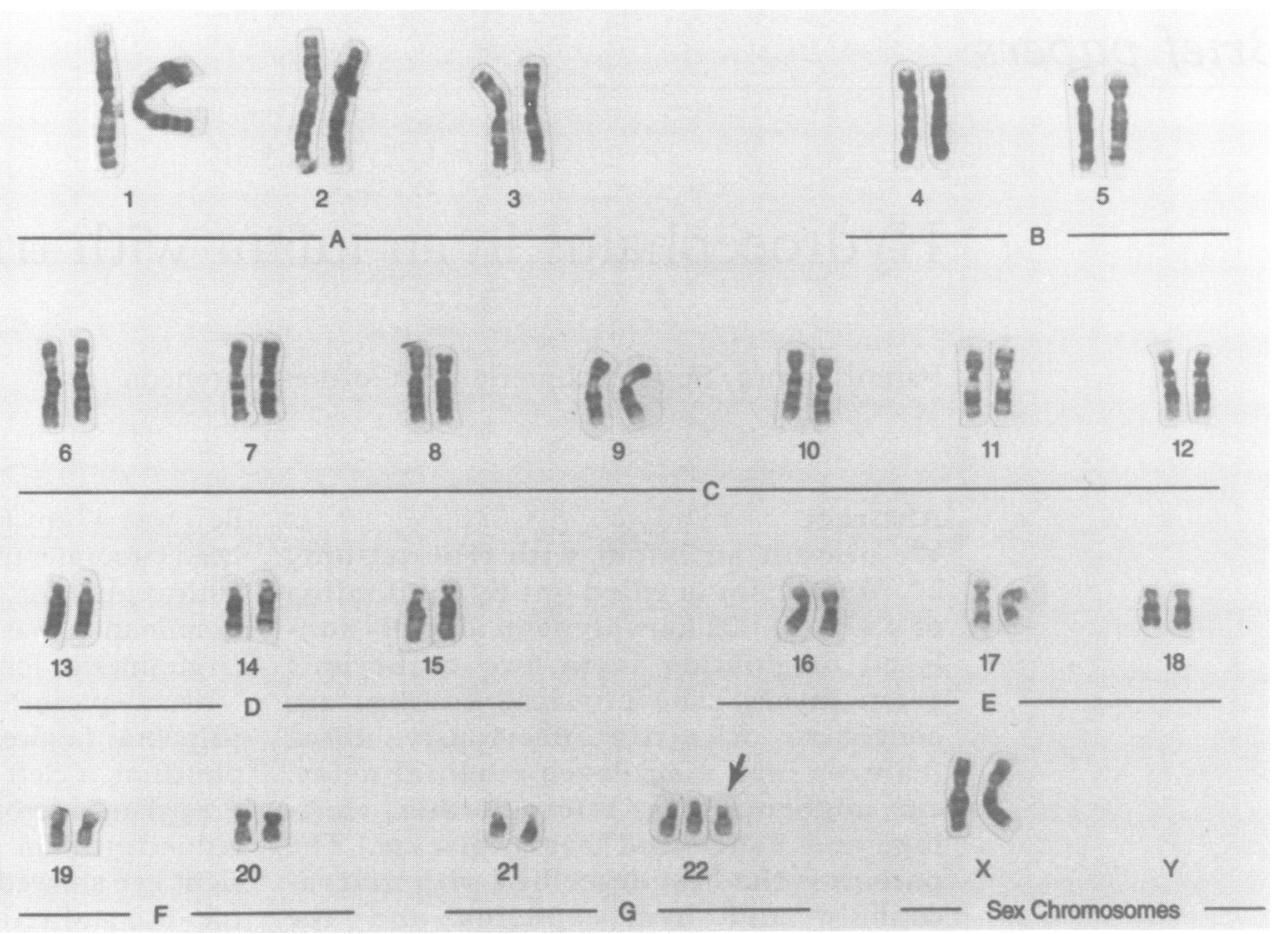

Figure $247, X X,+22$ karyotype from amniocytes.

iorly and posteriorly. There was an inferior coloboma with intact disc of the left eye. The infant had widely spaced nipples, hypoplastic nails, and rocker bottom feet. The neurological examination was notable for generalised hypotonia.

Chromosome analysis of peripheral blood confirmed the prenatal diagnosis of a $47, \mathrm{XX},+22$ karyotype (fig 4). Additional laboratory studies included cranial ultrasound and CT which confirmed the presence of hydrocephalus (fig 5). Echocardiography showed the presence of a patent ductus arteriosus, pulmonary valve insufficiency, and pulmonary hypertension. A gastrostomy tube was inserted because of feeding difficulty. A ventriculoperitoneal shunt was placed for management of the hydrocephalus. The infant died at the age of 4 months secondary to respiratory distress.

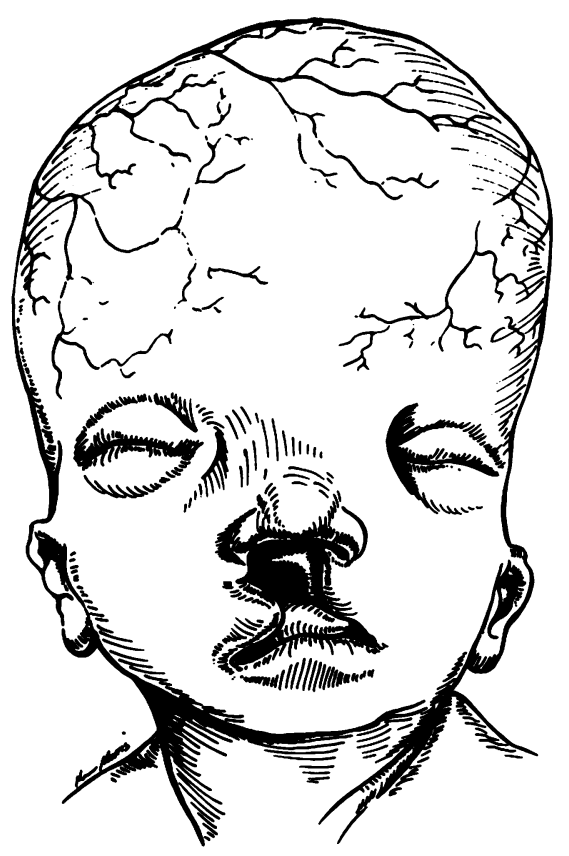

Figure 3 Drawing of craniofacial features showing macrocephaly, low set ears, epicanthic folds, downward slanting palpebral fissures, flat nasal bridge, long philtrum, cleft lip, and micrognathia.
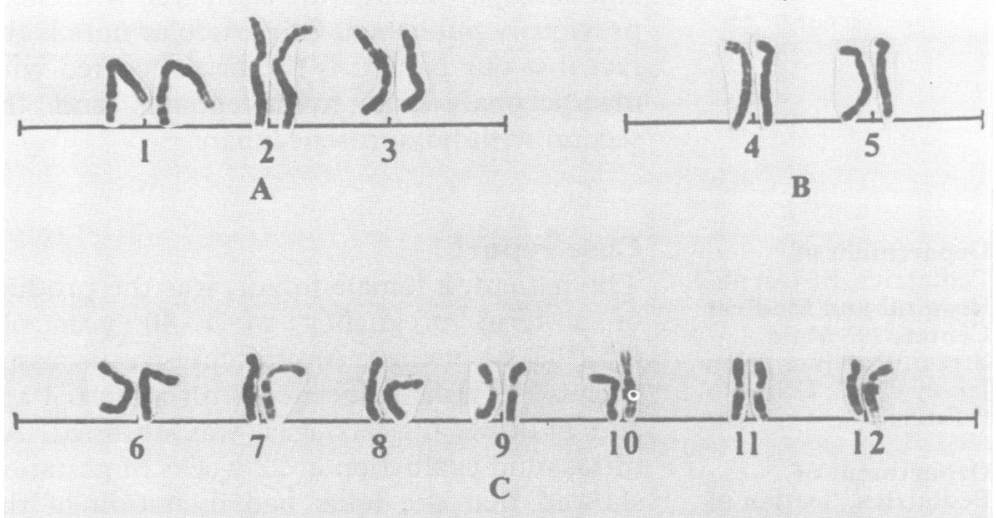
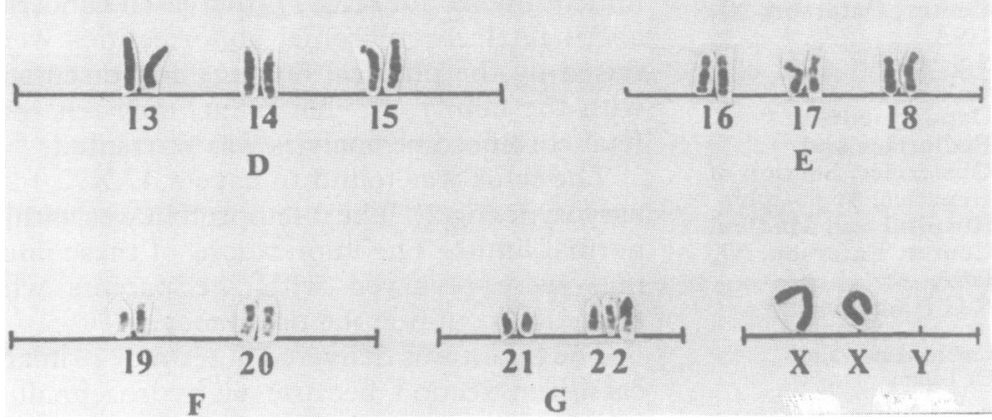

Figure $447, X X,+22$ karyotype from peripheral blood. 


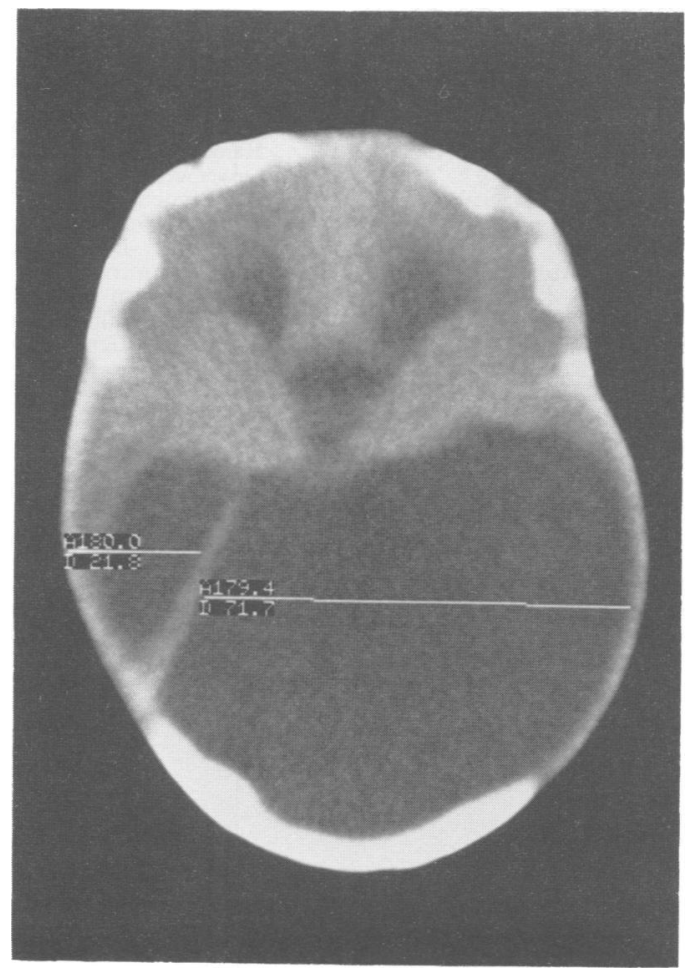

Figure 5 CT scan of head showing hydrocephalus.

\section{Necropsy findings}

Necropsy showed hydrocephalus, arhinencephaly, holoprosencephaly (semilobar type), and polymicrogyria. In addition there was a cleft lip and palate with micrognathia; a persistent left superior vena cava, patent ductus arteriosus, right subclavian artery arising from the aortic arch distal to the left subclavian artery, and an atrial septal defect with ventricular septal defect (membranous type); atelectasis of the left upper lung; malrotation of the colon with the caecum in the left upper quadrant; hepatomegaly; an accessory spleen; and rudimentary internal genitalia. Histopatholo-

Reported frequency of features in 27 patients with trisomy 22 compared with those of the present case

\begin{tabular}{lcc}
\hline Manifestations & $\begin{array}{c}\text { Published reports } \\
(\%) 22\end{array}$ & This patient \\
\hline Retardation of growth and development & 100 & + \\
Ear anomalies & 100 & + \\
Micrognathia & 85 & + \\
Congenital heart disease & 78 & + \\
Cleft lip/palate & 67 & + \\
Microcephaly & 63 & + \\
Genital hypoplasia & 56 & + \\
Hypertelorism & 56 & + \\
Renal malformation & 52 & + \\
Hypotonia & 48 & + \\
Broad nasal bridge & 48 & + \\
Short neck with pterygium & 41 & + \\
Hypoplastic nails & 41 & + \\
Downward slanting palpebral fissures & 37 & + \\
Epicanthic fold & 37 & + \\
Frontal bossing & 26 & + \\
Long philtrum & 22 & + \\
Arhinencephaly & 15 & + \\
Incomplete descent of caecum & 15 & + \\
Transverse palmar crease & 15 & + \\
Coloboma & 11 & + \\
Large anterior fontanelle & 7 & + \\
Holoprosencephaly & 4 & - \\
Absent corpus callosum & 4 & + \\
Diaphragmatic hernia & 4 & + \\
Goldenhar sequence & 4 & + \\
Macrocephaly & 0 & + \\
Hydrocephalus & 0 & + \\
\hline & &
\end{tabular}

gical studies showed mild pulmonary vascular changes suggestive of pulmonary hypertension, mild fatty metamorphosis of the liver, splenic congestion, and mild lymphocytic depletion of the thymus.

\section{Cytogenetics}

Chromosome studies were performed on cells originating from two embryonic germ cell layers. The first, epidermal, was represented by cells obtained through amniocentesis. The $47, \mathrm{XX},+22$ karyotype of the amniocytes is presented in fig 2 . The second, mesodermal, was represented by peripheral lymphocytes. Twenty cells were studied using Giemsa and trypsin banding techniques. The $47, \mathrm{XX},+22$ karyotype is shown in fig 4 .

\section{Discussion}

Chromosome 22 is a short, $52 \mathrm{mb}$ chromosome. Genes for lambda immunoglobin, myoglobin, ribosomal RNA, and neurofibromatosis type 2 are among those carried on the chromosome. ${ }^{12}$ Although the frequency of trisomy 22 in spontaneous abortions $(29 / 1000)$ is equivalent to that of trisomy $21(26 / 1000)$, it is a rare condition in the newborn. ${ }^{3} \mathrm{~A}$ short postnatal life span is characteristic of trisomy 22 . The oldest reported patient with a life span of 20 years seems to have been an exception. ${ }^{4}$

Most published case reports are accompanied by chromosome analysis of lymphocytes alone. Mosaicism was not ruled out in all cases and may account for differences in reported features. In the present case cells from two tissue types confirmed the diagnosis of trisomy 22 and thus the physical features support a characteristic phenotype for trisomy 22 .

The characteristics of our patient compared with those previously reported $\mathrm{d}^{4-22}$ are shown in the table. It includes 27 cases that were diagnosed by banded chromosome analysis. It can be seen that the most common presenting features are ear anomalies, congenital heart disease, micrognathia, and cleft lip with or without cleft palate. All of these features were present in our patient. In addition, our patient had the less frequently noted features of holoprosencephaly, large anterior fontanelle, and coloboma. Finally, hydrocephalus and macrocephaly are unique to our patient.

\section{Conclusion}

Chromosome abnormalities must be considered in any infant with multiple congenital abnormalities. A diagnosis of a particular condition (for example, Down's syndrome or trisomy 13) is strongly suggested by the pattern of clinical features. Definitive diagnosis then follows with chromosome analysis. Our patient provides further evidence of a distinct phenotype for trisomy 22 . We also note the additional features of hydrocephalus and macrocephaly.

\footnotetext{
1 Kaplan J, Aurias A, Julier C, Prieur M, Szajnert M. Human chromosome 22, f Med Genet 1987;24:65-78.
} 2 McKusick VA, Amberger JS. The morbid anatomy of the 
human genome: chromosomal location of mutations causing disease. $\mathcal{F}$ Med Genet 1993;30:1-26.

3 Hassold T, Chen N, Funkhouser J, et al. A cytogenetic study of 1000 spontaneous abortions. Ann Hum Genet 1980;44:151-78.

4 Welter DA, Scharff L III, Teal NM, Thevaos TG. Trisomy 22 in a 20 year old female. Hum Genet 1978;43:34751.

5 Antle CM, Pantzar JT, White VA. The ocular pathology of trisomy 22: report of two cases and review. 7 Pediatr Opthalmol Strabismus 1990;27:310-14.

6 Kukolich MK, Kulharya A, Jalal SM, Drummond-Borg M. Trisomy 22: no longer an enigma. Am $\mathcal{f}$ Med Genet 1989;34:541-4.

7 Iselius L, Faxelius G. Trisomy 22 in a newborn girl with multiple malformations. Hereditas 1978;89:269-71.

8 Peterson MB, Hansen M, Djernes BW. Full trisomy 22 in a newborn infant. Ann Genet (Paris) 1987;30:101-4.

newborn infant. Ann Genet (Paris) 1987;30:101-4.
Voiculescu I, Back E, Duncan AMV, Schwaibold H, Schempp W. Trisomy 22 in a newborn with multiple Schempp W. Trisomy 22 in a newborn with

10 McPherson E, Stetka DG. Trisomy 22 in a liveborn infant with multiple congenital anomalies. Am $\mathrm{f}$ Med Genet with multiple

11 Alfi OS, Sander RG, Donnell GM. Trisomy 22: a clinically identifiable syndrome. Birth Defects 1975;5:241-5.

12 Cervenka J, Hansen CA, Franciosi RA, Gorlin RJ. Trisomy 22 with 'cat eye' anomaly. $\mathcal{F}$ Med Genet 1977;14:288-90.
13 Lalchev S, Tzancheva M, Markova R. A case of trisomy 22 with a probable Robertsonian translocation 21/22. Hum Genet 1978;45:219-33.

14 Shokeir MHK. Complete trisomy 22. Clin Genet 1978;14:139-46.

15 Sundareshan TS, Naguib KK, Al-Awadi SA, Redha MA Hamoud MS. Apparently nonmosaic trisomy 22: clinical report and review. Am F Med Genet 1990;36:7-10.

16 Penchaszadeh VB, Coco R. Trisomy 22. Two new cases and delineation of the phenotype. $\mathcal{F}$ Med Genet 1975;12:193-9.

17 Phillipson J, Benirschke K, Bogart M. Two live-born infants with trisomy 22. Pediatr Pathol 1990;10:1001-5.

18 Feret M, Galan F, Aguilar MS, Serrano JL, Cidras M, Garcia R. Full trisomy 22 in a malformed newborn female Ann Genet (Paris) 1991:34:44-6.

19 Isada NB, Bolan JC, Larsen JW Jr, Kent SG. Trisomy 22 with holoprosencephaly: a clinicopathologic study. Teratology 1990;42:333-6.

20 Kim EH, Cohen RS, Ramachandran P, Mineta AK Ramesh Babu V. Trisomy 22 with congenital diaphragmatic hernia and absence of corpus callosum in a live-

21 Vohra K, Verma RS, Concepcion L. Trisomy 22: report of a patient diagnosed as a neonate. Disease Markers a patient diagn $1987 ; 5: 13-18$.

22 Kobrynski L, Chitayat D, Zahed L, et al. Trisomy 22 and facioauriculovertebral (Goldenhar) sequence. $\mathrm{Am} \mathcal{F} \mathrm{Med}$ Genet 1993;46:68-71. 